\title{
CdSe reinforced polythiophene nanocomposites as excellent materials for diode applications
}

\author{
R. Sing $h^{1 *}$, A. K. Shrivastava ${ }^{1}$, A. K. Bajpai ${ }^{2}$ \\ ${ }^{1}$ School of Studies in Physics, Jiwaji University, 474011 Gwalior, India \\ ${ }^{2}$ Bose Memorial Research Lab, Dept. of Chemistry, Govt. Autonomous Science College, 482002 Jabalpur, India
}

Received 2 April 2020; accepted in revised form 20 June 2020

\begin{abstract}
In the present work, nano-rods of mixed semiconductors were reinforced to conducting polymers to get their composites. CdSe semiconductor nanoparticles were reinforced into the conducting polymer polythiophene (PTh) at room temperature following an oxidation polymerization method. This method was rapid, cost effective and produced larger yield of polymer. X-ray diffraction (XRD) data of composites revealed that the crystallite size was of the order of 45-47 nm. Field emission scanning electron microscopic (FESEM) analysis showed horizontal cross section of CdSe nanoparticles after they were embedded into the PTh matrix. In the composites phase, the nano-rods of CdSe were seen lying over the PTh matrix. $\mathrm{UV}$-Vis spectral studies showed reduction in the energy band gap from $3.05 \mathrm{eV}$ of native PTh to $2.26 \mathrm{eV}$ of PTh/CdSe nanocomposites I-V plots of nanocomposites comprising of p-type PTh and n-type CdSe showed similar characteristics as those of the junction diode. The DC conductivity and short circuit current $\left(J_{\mathrm{sc}}\right)$ of $\mathrm{PTh} / \mathrm{CdSe}$ nanocomposites indicated drastic changes as compared to those of the pure PTh. Since, I-V plot of nanocomposites phase resembled well with that of a junction diode, the as-synthesized materials has potential to be used in diode applications.
\end{abstract}

Keywords: polymer nanocomposites, nanoparticles, polythiophene, conductivity, diode

\section{Introduction}

Polymers are often known for their lower conductivity. Certain polymers, due to the presence of delocalized $\pi$-electron systems, show charge mobility and enhanced polarization and called as conducting polymers. The conducting polymers have long chain of conjugated molecules having $\sigma$ and $\pi$ bonds [1]. These polymers are light weight, flexible, cost-effective, moderately conducting and easily polarizable [2-4]. Among the family of conducting polymers such as polythiophene (PTh), polyaniline (PANI), polypyrrole (PPy), etc. the PTh has received special attention due to its low production cost, excellent thermal, chemical and environmental stability, high electrical conductivity and facile synthesis [5]. PTh consists of linear chains of thiophene (Th) molecules and exhibits conduction property when electrons are added or removed from the $\pi$-conjugated orbitals via doping [6-14]. PTh has $\sigma$ and $\pi$ bonds and is an intrinsically conducting polymer having large $\pi$-conjugated structure, flexibility, high conductivity, and ease of doping. A number of derivatives of this conducting polymer have also been reported in literature [15-19].

Semiconductors are materials which show conductivity and their conductivity can be tailored with the addition of either trivalent or pentavalent impurities. Moreover, semiconductors such as CdSe has a band gap that is best suited for materials like nanocomposites. In recent years, photovoltaic devices, solar cells, and junction diodes have been fabricated by judicious combination of p-type conducting polymers and n-type inorganic semiconductor nanoparticles [10]. Due to high electron mobility in inorganic 
semiconductors and charge transfer mechanism in conducting polymers, conducting polymer-inorganic nanocomposites heterojunctions have been used in various applications, such as photovoltaic cells, actuators, electrolytes membrane, solar cells, light emitting diodes, optoelectronics devices [20-22] lithium ion batteries, sensors, and super-capacitors [23-25]. Nanoparticles of CdSe are known to improve the electrical conduction properties of conducting polymers. Their association with conduction polymers provides new materials which possess properties of both of its native constituents. Moreover, some of their properties are so much enhanced that they become superior to polymers and semiconductors. CdSe is an inorganic semiconductor having a direct band gap of $1.74 \mathrm{eV}[26,27]$. The quantum dots (QDs) of CdSe are frequently used as inorganic nanosized materials due to their excellent physical, electronic, optical and structural properties [28]. II-IV semiconductor CdSe QDs are inorganic particles having size less than $10 \mathrm{~nm}$. Particles of CdSe are quantum confined because their size is less than the Bohr radius which results in an increased electrical performance of nanoparticles [29, 30]. Acharya et al. [31] studied the optical and structural properties of $\mathrm{PTh} / \mathrm{CdSe}$ nanocomposites and found that the energy band gap of $\mathrm{PTh} / \mathrm{CdSe}$ nanocomposites is higher than that of the native CdSe. Furthermore, they also measured the electrical properties of as-prepared nanocomposite and published their results elsewhere [32]. AlFannakh et al. [33] investigated electrical and kinetic thermal analysis of polyaniline/poly(vinyl alcohol) magnetite nanocomposites film and found enhancements in thermal stability, activation energy and electrical conductivity of PANI/PVA magnetite $\left(\mathrm{Fe}_{3} \mathrm{O}_{4}\right)$ nanocomposite as compared to those of thePANI/PVA blends. In the present work, CdSe nanoparticles have been synthesized through solution route and PTh was obtained by polymerization of thiophene. Both of them were mixed to get the CdSe reinforced PTh nanocomposites and their electrical properties have been investigated.

\section{Experimental techniques}

\subsection{Materials}

The chemicals used for the synthesis of nanocomposites were cadmium acetate dihydrate $\left(\left(\mathrm{CH}_{3} \mathrm{COO}\right)_{2} \mathrm{Cd} \cdot 2 \mathrm{H}_{2} \mathrm{O}\right)(98 \%)$, selenium $(\mathrm{Se})$ (metal) powder $(99 \%)$, thiourea $(99 \%)$, thiophene $(99 \%)$, ferric chloride $\left(\mathrm{FeCl}_{3}\right)(96 \%)$, chloroform $\left(\mathrm{CHCl}_{3}\right)$
(99.5\%), triethanolamine (TEA) (97\%) and nitric acid $\left(\mathrm{HNO}_{3}\right)(71 \%)$. All chemicals were procured from Thermo Fisher Scientific India Pvt. Ltd. \& Central Drug House, New Delhi, India.

\subsection{Synthesis of polythiophene}

PTh was synthesized by following an oxidation polymerization method. In a typical experiment, $1.18 \mathrm{M}$ Th was added into $40 \mathrm{ml}$ chloroform to prepare the monomer solution which was further stirred and ultra-sonicated for $10 \mathrm{~min}$. $\mathrm{FeCl}_{3}(0.5 \mathrm{M})$, used as an oxidant, was added to $40 \mathrm{ml}$ chloroform and stirred for $15 \mathrm{~min}$ to produce a clear solution. The prepared oxidant solution was added dropwise into the Th solution for polymerization. The resulting solution was further ultrasonicated at $20 \mathrm{KHz}$ frequency and after completion of the ultrasonication, the solution was kept at $4{ }^{\circ} \mathrm{C}$ for $6 \mathrm{~h}$ to complete the polymerization reaction. After completion of the polymerization process a viscous solution was obtained this was filtered, and washed several times with distilled water and acetone to remove the impurities and un-reacted chemicals. The material so obtained was dark brown in color. After drying it at room temperature for 2 days, the black colored solid material of PTh having. 90-95\% yield was obtained which was crushed to powder, and stored in airtight glass tubes for subsequent studies.

\section{Mechanism of polymerization of thiophene}

The formation of PTh follows an oxidation polymerization mechanism as given below (Equation (1)-(4)):

$$
\begin{array}{ll}
\mathrm{Th}+\mathrm{Fe}^{3+} & \rightarrow \mathrm{Th}^{\bullet+}+\mathrm{Fe}^{2+} \\
2 \mathrm{Th}^{\bullet+} & \rightarrow \mathrm{Th}-\mathrm{Th}+2 \mathrm{H}^{+} \\
\mathrm{Th}-\mathrm{Th}+\mathrm{Fe}^{3+} & \rightarrow \mathrm{Th}-\mathrm{Th}^{\bullet+}+\mathrm{Fe}^{2+} \\
\mathrm{Th}_{-} \mathrm{Th}^{\bullet+}+\mathrm{Th}^{\bullet+} & \rightarrow \mathrm{Th}-\mathrm{Th}-\mathrm{Th}+2 \mathrm{H}^{+}
\end{array}
$$

As shown in Equation (1), thiophene molecule is oxidized by the ferric ion to produce a radical cation $\left(\mathrm{Th}^{\circ+}\right)$ which further dimerizes to give a dimer of thiophene (Th-Th) releasing two protons (Equation (2)). This dimer is further oxidized by ferric ion to form dimer ion- radical of thiophene $\left(\mathrm{Th}-\mathrm{Th}^{\bullet+}\right)$ which subsequently reacts with thiophene ion-radical to give a trimer (Th-Th-Th). In general, the whole mechanism may be presented as given below (Equations (5), (6)): 


$$
\begin{aligned}
& (\mathrm{Th}-\mathrm{Th})_{\mathrm{n}}+\mathrm{Fe}^{3+} \rightarrow(\mathrm{Th}-\mathrm{Th})_{\mathrm{n}}{ }^{{ }^{++}+\mathrm{Fe}^{2+}} \\
& (\mathrm{Th}-\mathrm{Th})_{\mathrm{n}}{ }^{++}+\mathrm{Th}^{\cdot+} \rightarrow(\mathrm{Th}-\mathrm{Th})_{\mathrm{n}+1}+2 \mathrm{H}^{+}
\end{aligned}
$$

Thus, these reactions lead to the formation of PTh.

\subsection{Synthesis of CdSe nanoparticles}

CdSe nanoparticles were prepared by the co-precipitation method as shown in Figure 1. In this method, few drops of $\mathrm{HNO}_{3}$ were added to $2.53 \mathrm{M}$ of Se metal powder and, thereafter, $20 \mathrm{ml}$ double distilled water was added dropwise into the above mixture. This solution was refluxed at $9^{\circ} \mathrm{C}$ for $13 \mathrm{~h}$ under constant stirring and the solution was filtered and allowed to cool in dark. This was marked as solution 'A'. Another solution ' $\mathrm{B}$ ' was prepared by mixing $2 \mathrm{M}$ thiourea and $10 \mathrm{ml}$ distilled water by stirring for $30 \mathrm{~min}$. Another solution ' $\mathrm{C}$ ' was prepared by mixing $1.5 \mathrm{M}$ cadmium acetate and $20 \mathrm{ml}$ distilled water and stirred for $1 \mathrm{~h}$. Thereafter, the solution ' $\mathrm{B}$ ' was added dropwise into the solution ' $\mathrm{C}$ ' to get cadmium sulphide. Afterwards, the Se solution, that is solution 'A', was slowly added into the cadmium sulphide solution. On addition of Se solution into the CdS solution, the color of the resulting solution turns milky within $10 \mathrm{sec}-$ ond. Soon after few seconds it turns yellow, after few minutes to orange, then to red, and finally it turns dark red. For the synthesis of CdSe nanoparticles, thiourea was used as a stabilizing agent or precursor which increases the stability of the CdSe nanoparticles [34]. In a typical experiment, $3 \mathrm{~mL}$ TEA was added to final solution to control the growth of nucleated particles. The $\mathrm{pH}$ of the above solution was maintained at 12 by adding aqueous ammonia solution drop by drop. The $\mathrm{pH}$ was monitored continuously, and if there was any fluctuation in the $\mathrm{pH}$ values, it was adjusted by adding additional amount of aqueous ammonia. The precipitate of CdSe was separated out and centrifuged at
$9000 \mathrm{rpm}$ for $10 \mathrm{~min}$. The centrifugation process was repeated $4-5$ times and thereafter, the material was isolated and washed several times with distilled water, and finally with acetone. The solid material so obtained was dried in hot air oven at $200{ }^{\circ} \mathrm{C}$ for $6 \mathrm{~h}$. Then, it was taken out and crushed properly to get powdered CdSe and stored in airtight glass tubes. From the present method $60-70 \%$ yield of CdSe was obtained. The reactions involved in the formation of CdSe may be given as below (Equation (7)-(11)):

$$
\begin{array}{ll}
\mathrm{Se}(\text { Metal })+2 \mathrm{HNO}_{3} & \rightarrow \mathrm{H}_{2} \mathrm{SeO}_{3}+\mathrm{NO}_{2}+\mathrm{NO} \\
\mathrm{H}_{2} \mathrm{SeO}_{3} & \rightarrow\left(\mathrm{SeO}_{3}\right)^{2-}+2 \mathrm{H}^{+}
\end{array}
$$

$\left(\mathrm{SeO}_{3}\right)^{2-}+6 \mathrm{H}^{+}+6 \mathrm{e}^{-} \rightarrow \mathrm{Se}^{2-}+3 \mathrm{H}_{2} \mathrm{O}$ (due to moderate oxidizing nature)

$$
\begin{array}{ll}
\mathrm{Cd}\left(\mathrm{CH}_{3} \mathrm{COO}\right)_{2} & \rightarrow \mathrm{Cd}^{2+}+2 \mathrm{CH}_{3} \mathrm{COO}^{-} \\
\mathrm{Cd}^{2+}+\mathrm{Se}^{2-} & \rightarrow \mathrm{CdSe}
\end{array}
$$

The above reactions explain the mechanistic formation of CdSe nanoparticles.

\subsection{Synthesis of $P T h / C d S e$ nanocomposites}

$\mathrm{PTh} / \mathrm{CdSe}$ nanocomposites were prepared by following an oxidation polymerization method as shown in Figure 2. At first, $1.18 \mathrm{M}$ solution of Th was prepared and $70 \%$ of Th solution was irradiated with $20 \mathrm{kHz}$ frequency for ultrasonication. Thereafter, $1.2 \mathrm{~g}$ of CdSe nanoparticles were added into the ultrasonicated Th solution, stirred, and again ultrasonicated at $20 \mathrm{kHz}$ frequency to obtain a homogeneous suspension.

Now, $\mathrm{FeCl}_{3}(0.5 \mathrm{M})$ was dissolved in $40 \mathrm{ml}$ chloroform and stirred to prepare the oxidizing agent solution. This solution was added drop wise into the $\mathrm{Th} / \mathrm{CdSe}$ solution prepared as above with continuous

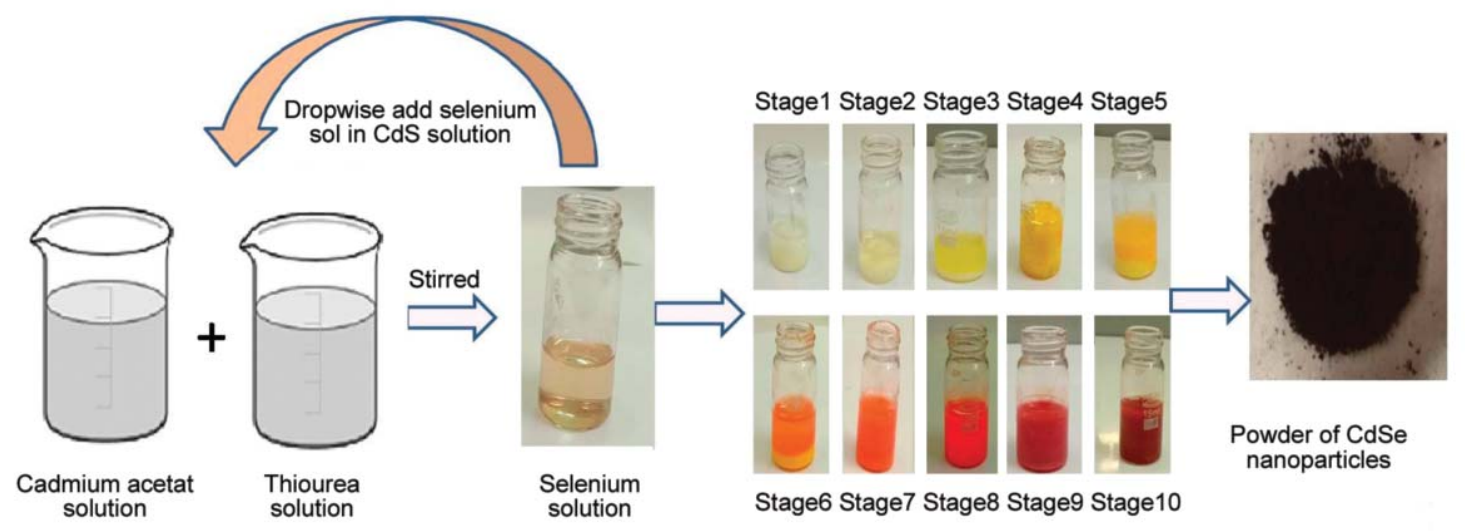

Figure 1. Different stages during synthesis of CdSe nanoparticles. 


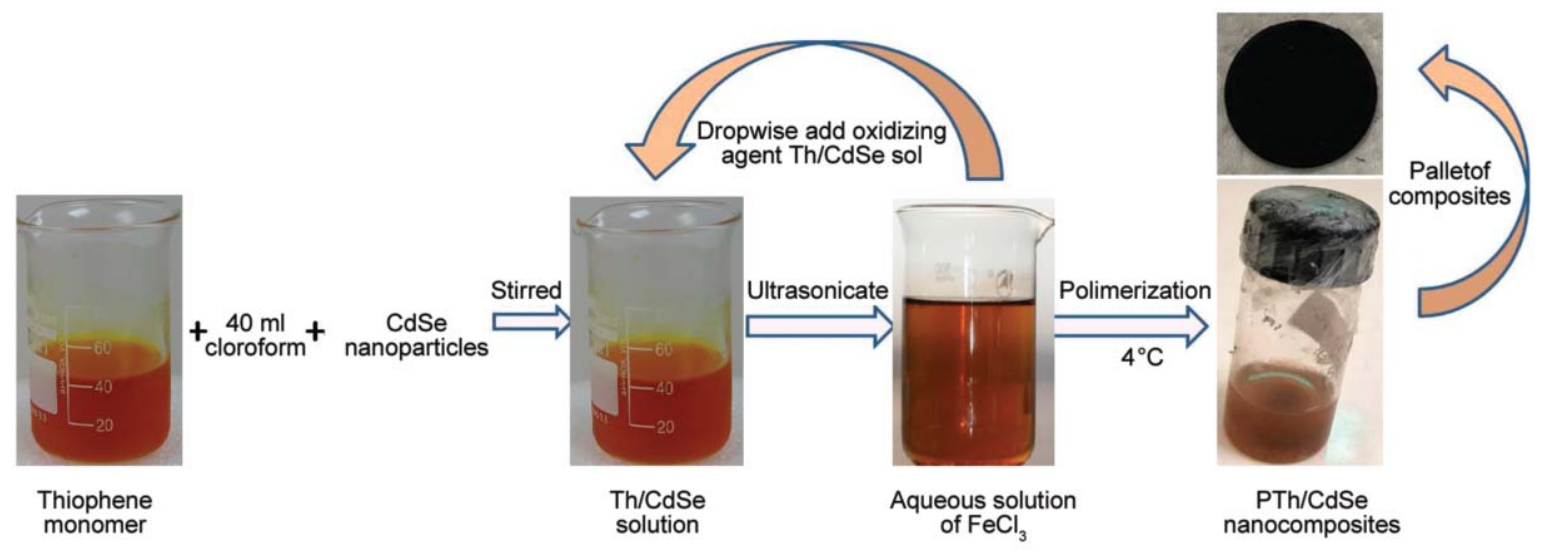

Figure 2. Synthesis of PTh/CdSe nanocomposites.

stirring. The resulting solution was kept at $4{ }^{\circ} \mathrm{C}$ for $12 \mathrm{~h}$ to complete the polymerization process. The material so obtained was dried at room temperature for 2 days till it turns into black. The material obtained was $\mathrm{PTh} / \mathrm{CdSe}$ nanocomposites which were obtained in larger yield and in lesser time.

The use of ferric chloride provides iron in the solution in addition to the cadmium $(\mathrm{Cd})$ and Se. The ionic radii of $\mathrm{Cd}$, $\mathrm{Se}$ and $\mathrm{Fe}^{3+}$ ions are in the order of 1.71, 1.22 and $0.6 \AA$, respectively which reveals that there is a greater probability of association of $\mathrm{Cd}$ with $\mathrm{Se}$ rather than with iron. The EDAX spectra of the obtained material are shown in Figure 4 which confirms the presence of $\mathrm{Cd}$, $\mathrm{Se}$ and $\mathrm{Fe}$ in different proportions.

\subsection{Fabrication of polymer - nanocomposites pellets}

The prepared powders of native PTh and PTh/CdSe nanocomposites were transformed into pellets by subjecting them to a pressure of $2000 \mathrm{lbs} / \mathrm{inch}^{2}$ using hydraulic press (Spectra lab model SL-89). The pressure was applied for $20 \mathrm{sec}$. The as-obtained pellets were subsequently used for their electrical and dielectric measurements.

\subsection{Characterization techniques}

In order to characterize the as-prepared samples, field emission scanning electron microscopy (FESEM), and energy dispersive X-ray analysis (EDAX) were performed using Carl Zeiss SIGMA 2-12 field emission scanning with electron microscope EDAX $\lambda$-METER, Germany. DC conductivity measurements were performed using an electrical probe station (Make: Ecopia, Model: EPS500) and a measuring unit (Make: Keithley, Model: 2450), Cleverland, Ohio, U.S. Dielectric study was done using a HIOKI-3532 LCR Hi-tester, Japan. XRD measurements were per- formed on Bruker D8-Discover system, UK at Synchrotrons Utilization Section, RRCAT, Indore (MP), India. The radiation used for the measurements was $\mathrm{Cu}-\mathrm{K}_{\alpha}$. The wavelength of $\mathrm{Cu}-\mathrm{K}_{\alpha}$ radiation was $\lambda=$ $1.5406 \AA$. Optical studies were performed on a Shimadzu UV-Vis spectrophotometer (UV-2450), Japan, over the wavelength range 200 to $900 \mathrm{~nm}$.

\section{Results and discussion}

\subsection{X-ray diffraction (XRD) analysis}

The XRD spectra of native PTh, pure CdSe and $\mathrm{PTh} / \mathrm{CdSe}$ nanocomposites are shown in Figure 3. The XRD spectra of native PTh shows a broad diffraction peak at $2 \theta=17.47^{\circ}$ corresponding to (001) plane which is associated with $\pi-\pi$ stacking structure in PTh chains and suggests for its partially amorphous nature. The similar observation has also been reported by Najar et al. [22]. XRD spectra of native CdSe represent diffraction peaks at $2 \theta$ values of $25,42,45$ and $49^{\circ}$, respectively. The planes corresponding to these

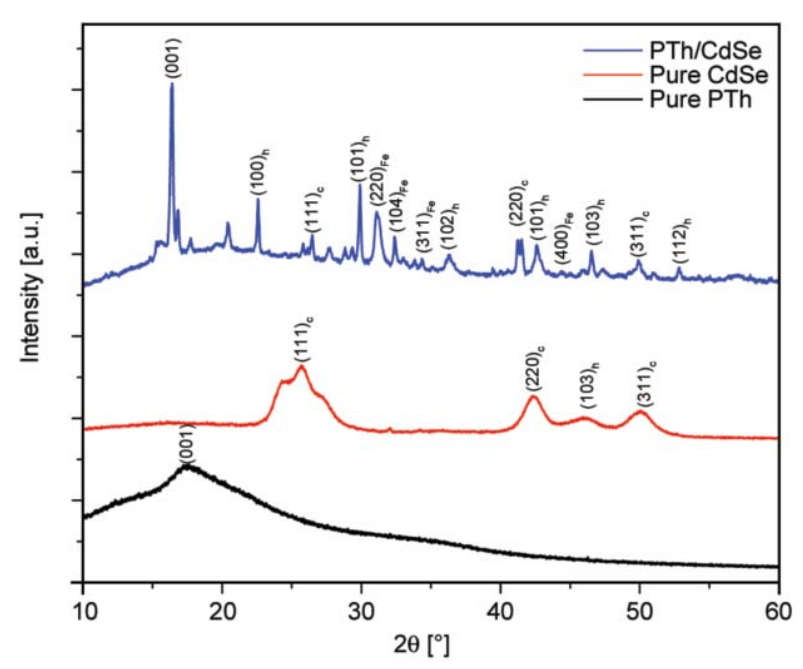

Figure 3. XRD spectra of native $\mathrm{PTh}$, pure CdSe, and PTh/ CdSe nanocomposites.
R1

$\mathrm{R} 2$

R3

R4

R5

R6

R7

R8 
peaks are $(111,220,311)$, and (103), respectively. The $(111,220,311)$ peaks correspond to cubic phase whereas the (103) plan corresponds to hexagonal phase. These peaks match well with those of JCPDS file (Card No. 19-0191, 77-2307 and 65-2891). The XRD spectra of composites show peaks at 26, 41 and $49^{\circ}$, indexed as $(111,220,311)$, respectively, corresponding to cubic phases whereas peaks at $2 \theta$ values $22,30,36,42,49$ and $52^{\circ}$ indexed as $(100,101,102$, $110,103,112)$ correspond to hexagonal phase. All these peaks match well with the JCPDS card no. 772306, 77-2307, 65-2891. In the XRD spectra of the composite several extra peaks are observed at $2 \theta$ values $31,32,34,45^{\circ}$ indexed as $(220,104,311,400)$, respectively which show the presence of iron $(\mathrm{Fe})$ in composites. The entire iron peaks match well with the JCPDS card no. 98-000-0064, 74-0748, 39-1346, 01-089-8103 [31-33]. Fe present in composites, due to $\mathrm{FeCl}_{3}$, was used as a polymerization initiator. The prominent peak (001) in PTh is broad and represents its partially amorphous nature $[35,36]$. On doping with CdSe the peak becomes sharp and changes to polycrystalline. The lattice constants of $\mathrm{CdSe}$ in $\mathrm{PTh} / \mathrm{CdSe}$ nanocomposites were found to be $a=$ $6.1 \AA$ for cubic phase, $a=3.936 \AA$, and $c=6.634 \AA$ for its hexagonal phase.

The crystallite size of nanocomposites was calculated using Debye Scherer's formula (Equation (12)) [37, 38]:

$D=\frac{K \lambda}{\beta \cos \theta}$

where $D$ is the crystallite size; $K$ is the Scherer's constant $(0.9) ; \lambda$ is the wavelength of radiation used (1.5406 $\AA$ ); $\theta$ is the Bragg's angle and $\beta$ is the full width of half maximum (FWHM) measured in radian. Since PTh is amorphous in nature, the particle size was not calculated. The crystallite size of pure CdSe was calculated from its XRD spectra and found to be about $3.0 \mathrm{~nm}$. The average crystallite size of the nanocomposite, when CdSe was added in to the PTh matrix, was calculated to be $47 \mathrm{~nm}$ for cubic phase and $45 \mathrm{~nm}$ for hexagonal phase [39]. The value of crystallite size, lattice parameters, miller indices, prominent peaks and other structural parameters of the present material has been measured and calculated and the results are summarized in Table 1.

The XRD results indicate that amorphous nature of native PTh changes into semi crystalline when CdSe was reinforced into the PTh matrix [40].

\subsection{Field emission scanning electron microscope (FESEM) analysis}

Surface morphology of native PTh and PTh/CdSe nanocomposites are shown in Figure 4 and 5, respectively. The surface morphology of native PTh can be seen in Figure 4. It is clear from the images that the PTh particles are perfectly spherical in shape having different dimensions. Some of the particles have nanometer size, whereas some of them are in micrometer range. In fact, both the micrographs reveal that the morphology of the particles seem spherical in shape and are well separated from each other having dimension in the range of $500 \mathrm{~nm}$ to $1 \mu \mathrm{m}$. When CdSe nanoparticles are added into the PTh matrix, the spherical morphology gets distorted, as clear from the Figure 5. Horizontal cross sections of CdSe nanoparticles which are arranged in parallel manner are clearly visible. Hexagonal rods like structures are formed on the PTh matrix surface. Similar spherical

Table 1. XRD data of native PTh, CdSe and PTh/CdSe nanocomposites.

\begin{tabular}{|c|c|c|c|}
\hline Parameters & Pure PTh & Pure CdSe & PTh/CdSe nanocomposites \\
\hline Crystal structure & Partially amorphous & Cubic and hexagonal & Cubic and hexagonal \\
\hline Prominent peak at $2 \theta \quad\left[{ }^{\circ}\right]$ & 17.47 & $\begin{array}{ll}25 & \text { (Cubic) } \\
49 & \text { (Hexagonal) }\end{array}$ & $\begin{array}{ll}22 & \text { (Cubic) } \\
42,52 & \text { (Hexagonal) }\end{array}$ \\
\hline Inter-planer spacing, $d[\AA]$ & 3.956 & $\begin{array}{ll}3.48 & \text { (Cubic) } \\
1.822 & \text { (Hexagonal) } \\
\end{array}$ & $\begin{array}{ll}3.93 & \text { (Cubic) } \\
2.12,1.732 & \text { (Hexagonal) }\end{array}$ \\
\hline FWHM, $\beta$ & 0.21 & $\begin{array}{ll}2.783 & \text { (Cubic) } \\
1.826 & \text { (Hexagonal) }\end{array}$ & $\begin{array}{l}0.145 \\
0.423,0.169\end{array}$ \\
\hline Miller indices $[h \mathrm{kl}]$ & {$[001]$} & $\begin{array}{ll}{[111]} & \text { (Cubic) } \\
{[103]} & \text { (Hexagonal) }\end{array}$ & $\begin{array}{l}\text { (Cubic) } \\
\text { (Hexagonal) }\end{array}$ \\
\hline Crystallite size & - & $\begin{array}{ll}3 & \text { (Cubic) } \\
5 & \text { (Hexagonal) }\end{array}$ & $\begin{array}{ll}47 & \text { (Cubic) } \\
45 & \text { (Hexagonal) }\end{array}$ \\
\hline Lattice parameter, $a \quad[\AA]$ & - & $\begin{aligned} a & =6 \quad \text { (Cubic) } \\
a & =3.936 \& c=6.634 \\
& \\
& \text { (Hexagonal) }\end{aligned}$ & $\begin{array}{rr}a=6.1 & \text { (Cubic) } \\
a=3.936 \& c=6.634 & \text { (Hexagonal) }\end{array}$ \\
\hline
\end{tabular}




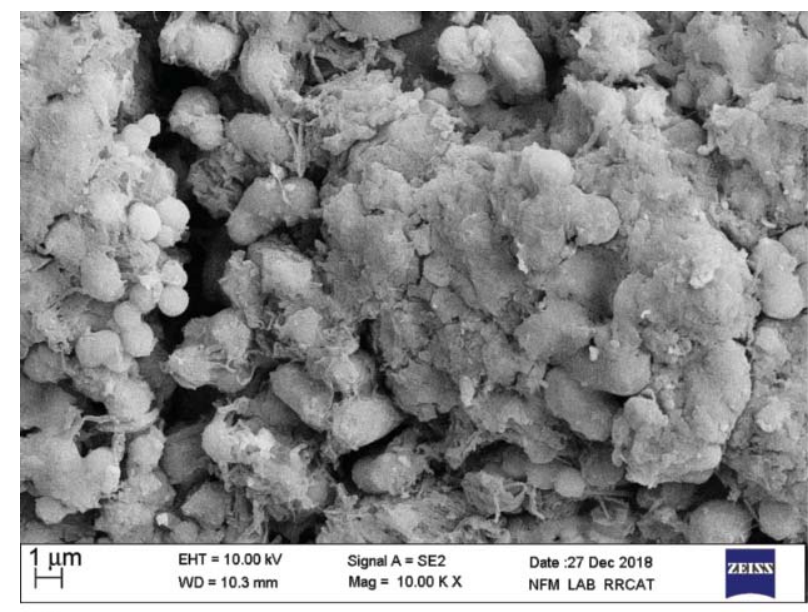

a)

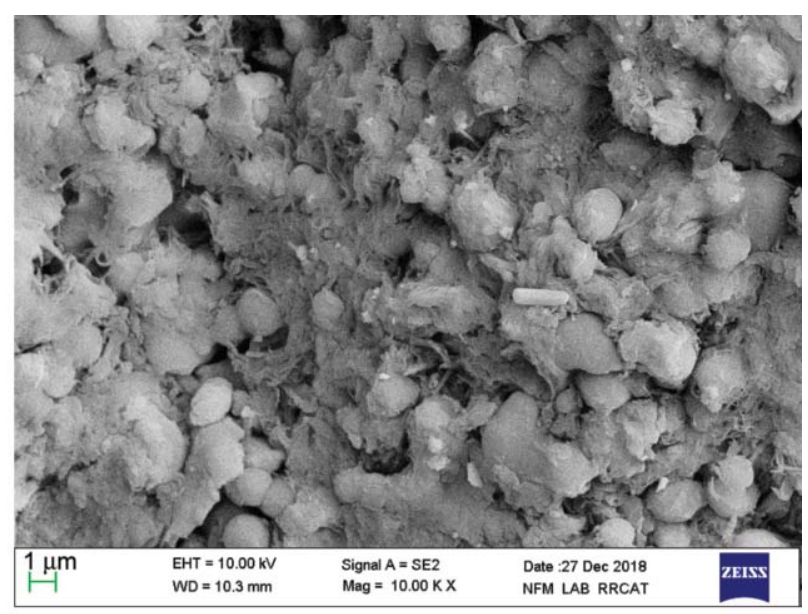

b)

Figure 4. FESEM images of pure PTh particles with magnification (a) $1 \cdot 10^{-6}$, (b) $1 \cdot 10^{-6}$.

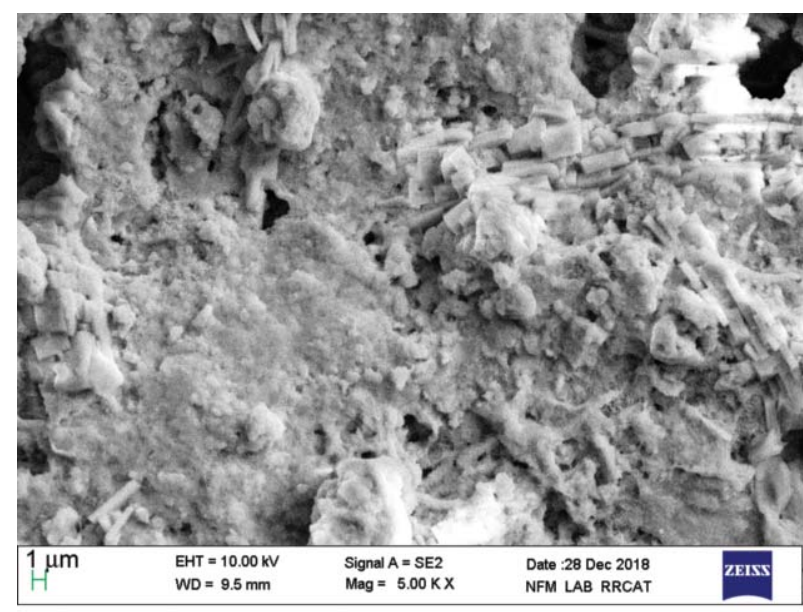

a)

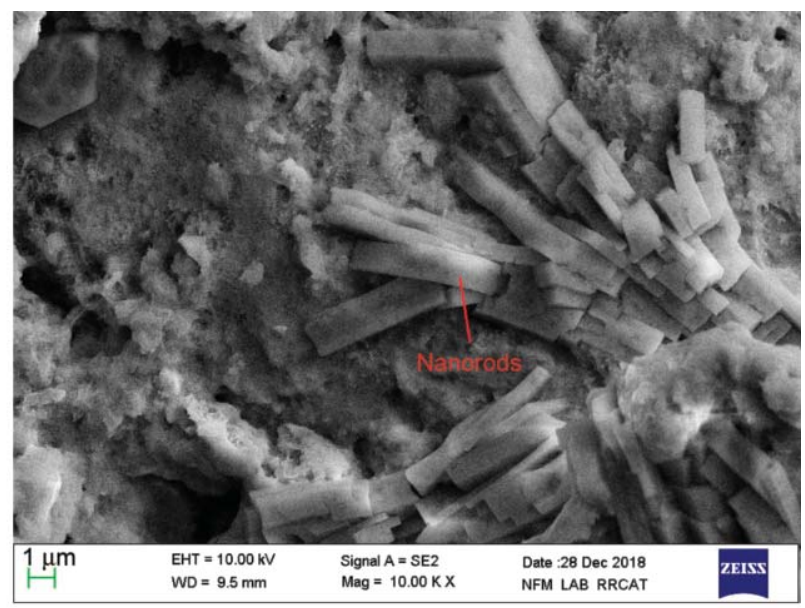

b)

Figure 5. FESEM images of PTh/CdSe nanocomposites with magnifications (a) $1 \cdot 10^{-6}$, (b) $1 \cdot 10^{-6}$.

morphology of PTh particles have also been reported by Pourabbas et al. [41].

\subsection{Elemental compositional study (EDAX)}

Elemental compositional study of native PTh and $\mathrm{PTh} / \mathrm{CdSe}$ nanocomposites were also performed and the results obtained are shown in Figure 6, respectively. EDAX spectra of native PTh shows the presence of elements $\mathrm{C}, \mathrm{O}, \mathrm{S}, \mathrm{Cl}$, and $\mathrm{Fe}$. Carbon and sulphur show the presence of $\mathrm{PTh}$ whereas $\mathrm{Cl}$ and $\mathrm{Fe}$ are present since $\mathrm{FeCl}_{3}$ was used as an oxidative polymerization initiator and $\mathrm{CHCl}_{3}$ as a solvent. EDAX spectra of $\mathrm{PTh} / \mathrm{CdSe}$ nanocomposites confirm the presence of $\mathrm{C}, \mathrm{O}, \mathrm{Se}, \mathrm{S}, \mathrm{Cl}, \mathrm{Cd}$, and Fe. Similarly, $\mathrm{Cd}$ and Se confirm the presence of CdSe in the PTh matrix.

Khanmohammadi et al. [5] have reported the presence of $\mathrm{Fe}$ in addition to $\mathrm{Mn}, \mathrm{O}, \mathrm{S}, \mathrm{C}$ and $\mathrm{Cl}$ in the EDAX spectra of $\mathrm{PTh} / \mathrm{MnO} 2$ nanocomposites. Ozkazanc [10] also reported EDAX spectra of PTh with different doping [\%] of zirconium (Zr). EDAX spectra show $\mathrm{Fe}(21.12)$ and $\mathrm{Zr}(0.650)$ [wt $\%$ ]. The authors also used $\mathrm{FeCl}_{3}$ as an oxidant for the polymerization purpose. Similar type of EDAX spectra were also observed in the present study.

\subsection{D.C. electrical measurements}

\subsubsection{Current-voltage plots}

Electrical measurements of native PTh and $\mathrm{PTh} / \mathrm{CdSe}$ nanocomposites were conducted using the two probe method. Current-voltage characteristics of PTh bulk (pellet) at room temperature are shown in Figure 7a. The potential was varied from 0 to $5 \mathrm{~V}$ and -5 to $0 \mathrm{~V}$, respectively so as to cover both the forward and the reverse bias. It was observed that the I-V characteristics of PTh are almost symmetrical with respect to Y-axis. It can be seen that in the beginning, the current increases linearly with the applied voltage but at later stage of the applied voltage, the increase in current turns non-linear. This non-linear increase of 

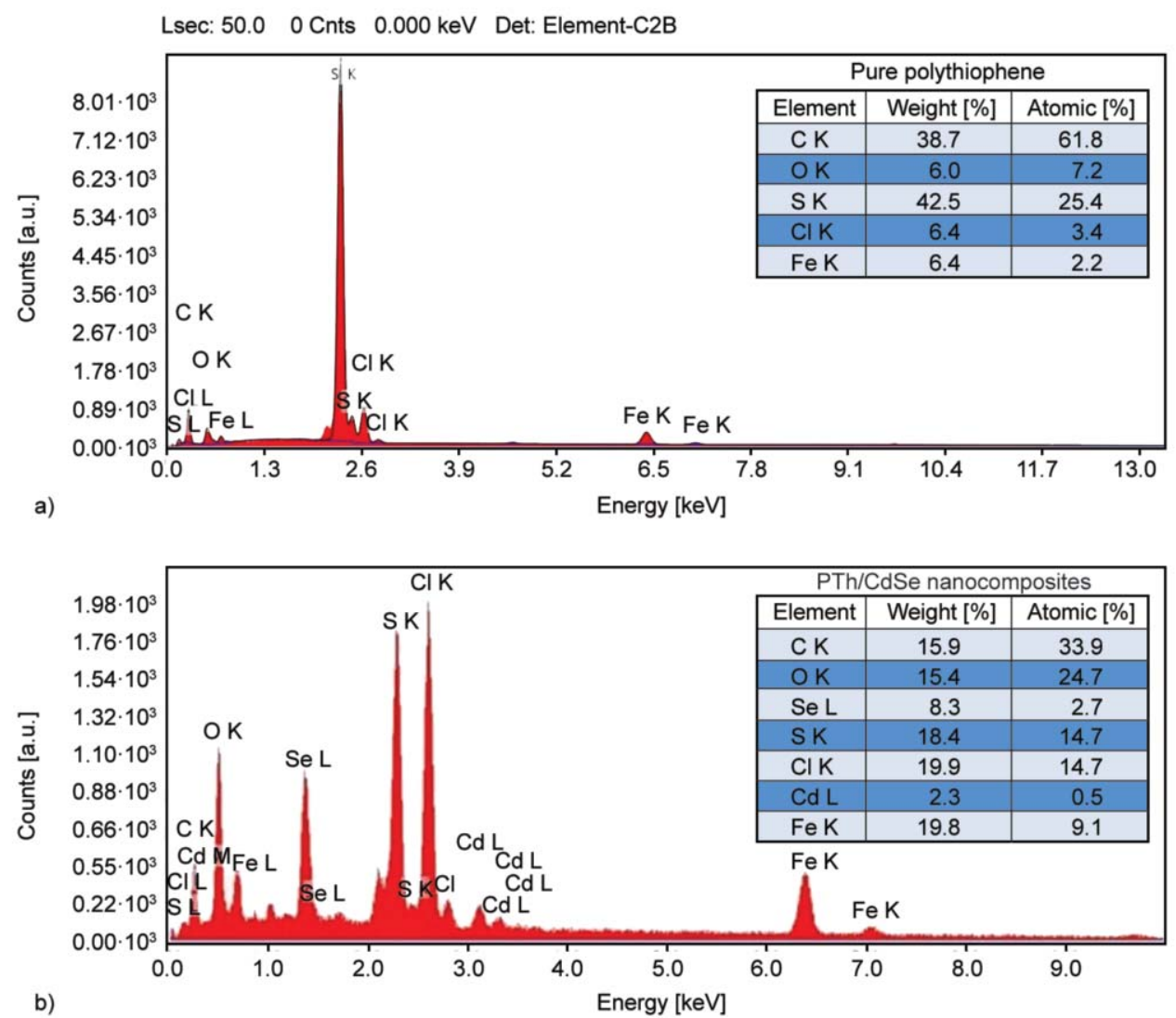

Figure 6. (a) EDAX spectral analysis of pure PTh, (b) EDAX spectral analysis of PTh/CdSe nanocomposites.

current with applied voltage can be related to the conduction mechanism in PTh [22]. In PTh, the conduction is carried out by free charge carriers 'polarons and bipolarons'. The number of polarons and bipolarons increases with the increase in applied voltage. This increase in charge carriers increases the current through the sample. Similar I-V plots of PTh at different temperatures have also been reported by Tiwari et al. [42].

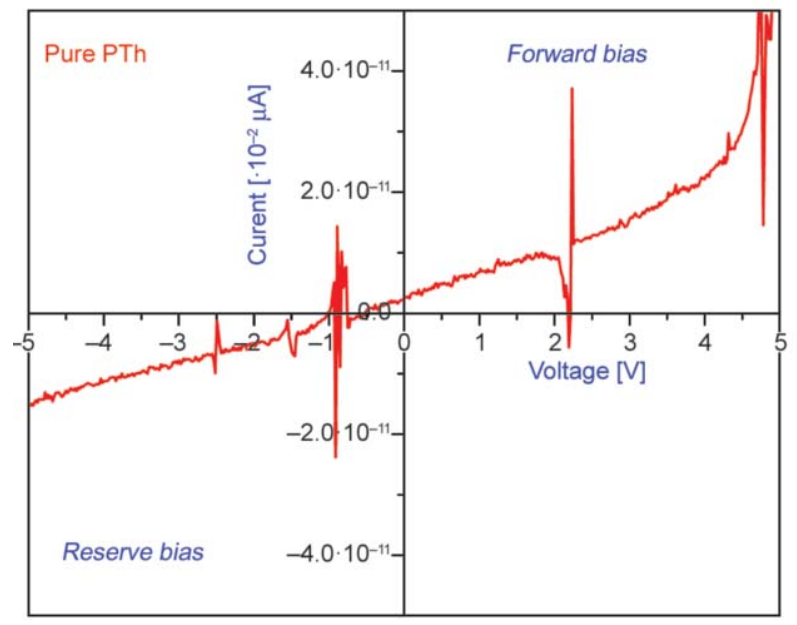

a)
The current-voltage characteristics of $\mathrm{PTh} / \mathrm{CdSe}$ nanocomposite at room temperature are shown in Figure $7 \mathrm{~b}$. Since PTh is a p-type material and CdSe is n-type, the pellets of $\mathrm{PTh} / \mathrm{CdSe}$ nanocomposites are expected to behave like P-N diode. In order to have forward bias, the one face of composite material pellet was made positive with respect to its other face. At lower voltage, the current rises due to the motion of polaron and electrons or holes. This results

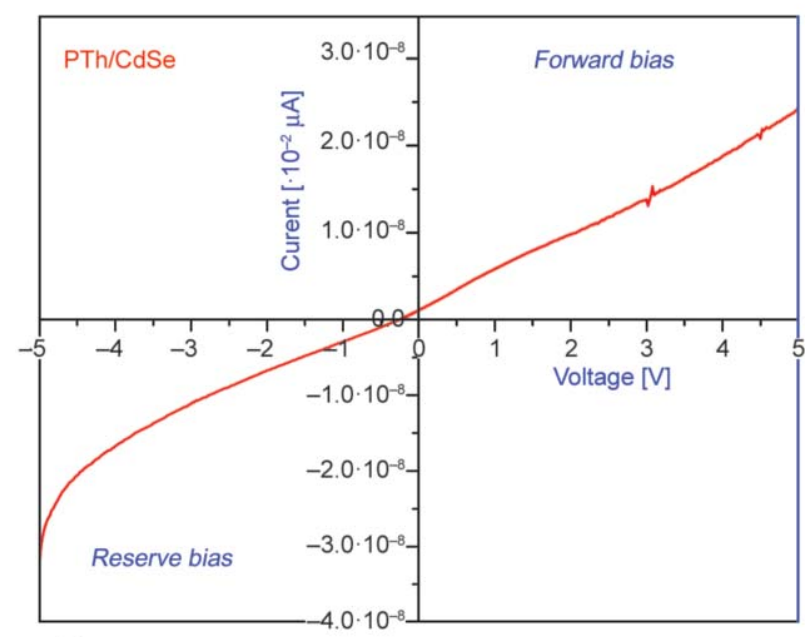

b)

Figure 7. (a) I-V characteristics of pure PTh, (b) I-V characteristics PTh/CdSe nanocomposites. 
in minimization of the width of depletion layer at the interface in between the pellet and the contact probe. In the reverse bias, width of the depletion layer increases due to high barrier potential. Here the current is just because of minority charge carriers which produce small current $[18,22,43]$. Similar electrical conduction in $\mathrm{CdS} /$ polyaniline heterojunction has also been reported by Patidar et al. [40] and Singh et al. [44] respectively.

\subsubsection{DC conductivity plot}

DC conductivity plots of native PTh and its nanocomposites $\mathrm{PTh} / \mathrm{CdSe}$ are shown in Figure 8. It is clear from the plots that the DC conductivity initially decreases rapidly with increasing potential and finally attains a constant value. The initial decrease in conductivity can be related to the mutual interaction between the charge carriers which enhances the resistivity. At higher potential, however, the induced electric field causes the net force to become operative and hence the conductivity attains a constant value. In composites, the order of conductivity is greater in comparison to that in the native PTh which is expected also because of the presence of semiconductor CdSe. On comparing the EDAX spectra of pure $\mathrm{PTh}$ and its composite with CdSe, it is clear that the impurities of $\mathrm{Fe}, \mathrm{Cl}, \mathrm{S}, \mathrm{C}$ and oxygen which are present in pure PTh are also present in the composite. The extra elements which are present in the composite are $\mathrm{Cd}$ and $\mathrm{Se}$, whose presence is reflected in EDAX results. Therefore, the enhanced conductivity in the composite phase might be due to the presence of $\mathrm{Cd}$ and $\mathrm{Se}$. The nature of variation of conductivity in both the materials remains same as similar mechanism of conduction is operative in composite

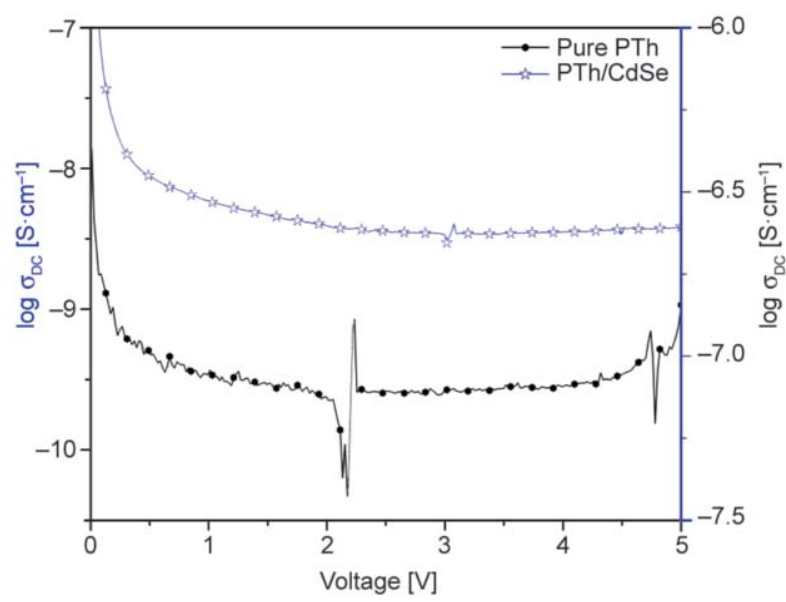

Figure 8. DC Conductivity vs. voltage of native PTh and $\mathrm{PTh} / \mathrm{CdSe}$ nanocomposites. materials. The increased hindrance in the composite puts obstacles in the charge transfer to inter and intra chains through hopping process. Finally, at higher potential the DC conductivity becomes constant with respect to the applied voltage. Kaneto et al. [45] also reported variation in DC conductivity with temperature. Nasrollahzadeh et al. [46] have reported an enhancement in electrical conductivity of PTh-carbon nanocomposites with increasing temperature in comparison to pure PTh.

The DC conductivity of composites was calculated using the formula reported in the literature [47, 48]. It is observed that when CdSe is mixed with PTh matrix, the DC conductivity increases from $10^{-9}$ to $10^{-7} \mathrm{~S} \cdot \mathrm{cm}^{-1}$. The observed order of conductivity in composite phases lies in the range of conductivity of semiconducting ions like $\mathrm{Cd}$ and Se. Thus, it can be inferred that the increased conductivity is due to the presence of $\mathrm{Cd}$ and Se ions [49-51]. The conductivity and resistivity are related by the relation (Equation (13)):

$\sigma=\frac{1}{\rho}$

where $\rho$ is the resistivity of the material defined by the formula [48] given below (Equation (14)):

$\rho=\left(\frac{V}{l}\right)\left(\frac{A}{l}\right)$

where $A$ is the surface area and $l$ is the thickness of the pallet [48]. The enhanced DC conductivity of $\mathrm{PTh} / \mathrm{CdSe}$ in comparison to that of the native PTh shows that the nanocomposites may be used for device fabrication that may be suitable for energy storage such as in batteries and diodes. Kamat and Chandraprabha have also reported the DC conductivity of PTh at different potentials $[18,44,52]$.

\subsubsection{Current density analysis}

The variation in current density for native PTh and $\mathrm{PTh} / \mathrm{CdSe}$ nanocomposites in forward bias $(0-5 \mathrm{~V})$ are shown in Figure 9. It is clear from the figure that the current density in the native PTh and composites increases with increasing voltage in the forward bias which might be due to the internal charge transfer and inter molecular interaction between the polaronpolaron, polaron-bipolaron and polaron-free charge carriers, as reported by Kamat et al. [52] and Singh et al. [54]. In the reverse ( -5 to $0 \mathrm{~V})$ bias also, the current density in the native $\mathrm{PTh}$ and $\mathrm{PTh} / \mathrm{CdSe}$ 


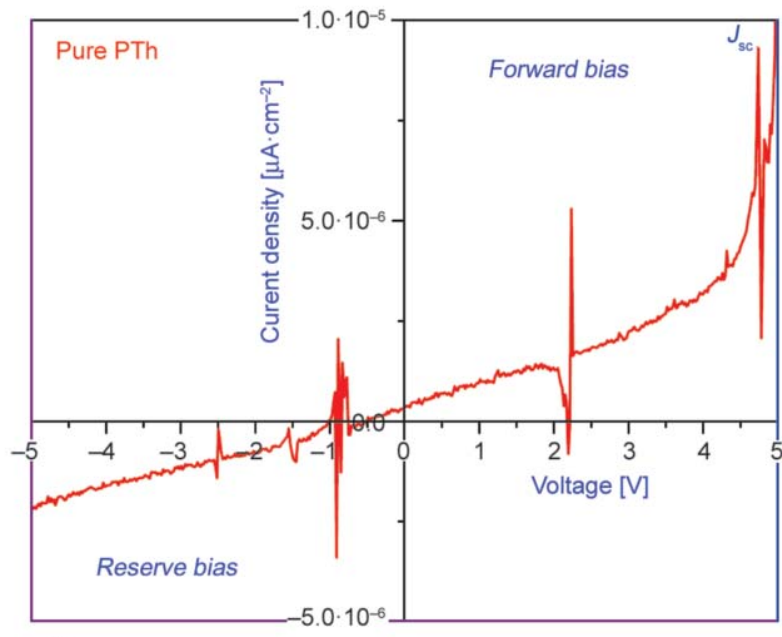

a)

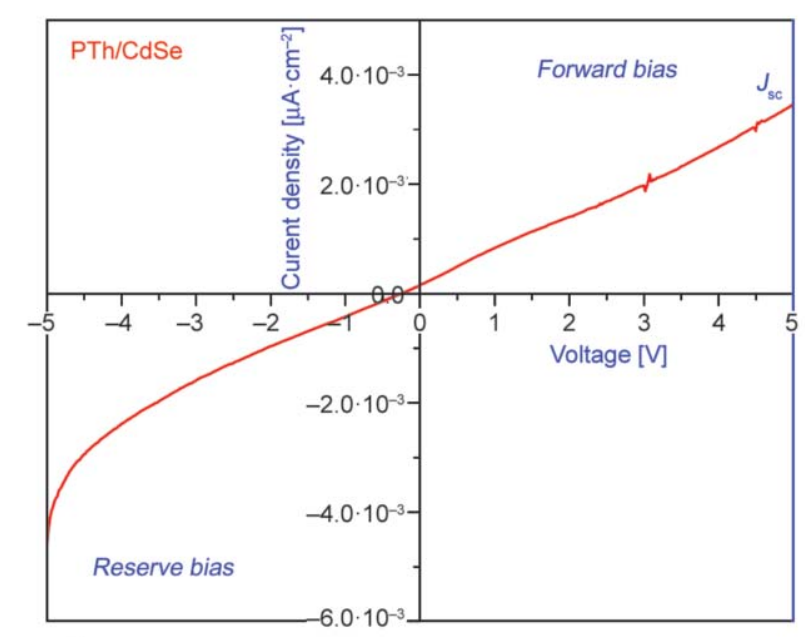

b)

Figure 9. (a) $J-V$ plot of native PTh, (b) $J-V$ plot of pPTh/CdSe nanocomposites.

nanocomposites increases which might be due to migration of polarons and minor charge carriers of CdSe. The short circuit current $\left(J_{\mathrm{sc}}\right)$ increases from $10^{-5}$ to $3.5 \cdot 10^{-3} \mu \mathrm{A} \cdot \mathrm{cm}^{-2}$ when CdSe was reinforced into the PTh matrix. This might be due to the increased $\mathrm{PTh} / \mathrm{CdSe}$ interface area and improved conduction path for charge extraction. Because of the enhancement in short circuit current $\left(J_{\mathrm{sc}}\right)$ in the nanocomposites phase, the nanocomposites may be used for fabrication of energy storage devices and in various potential applications in electronic industries $[23,53,55]$. Seidler and his co-workers [56], have reported that the current density of poly(3-alkylthiophene) (P3HT) film increases with increasing voltage which might be due to intra-chain charge transfer, intermolecular interaction, $\pi$-conjugation length etc. They have also measured short circuit current $\left(J_{\mathrm{sc}}\right)$ of $(\mathrm{P} 3 \mathrm{HT})$ between 8 to $10 \mathrm{~mA} \cdot \mathrm{cm}^{-2}$ for the fabrication of photovoltaic solar cell. Vijeth et al. [57], have fabricated $\mathrm{PTh} / \mathrm{Al}_{2} \mathrm{O}_{3}$ nanocomposites based asymmetric supercapacitor (ASC) as an anode electrode and charcoal as a cathode electrode and also measured its maximum current density for ASC device application. Nasrollahzadeh et al. [46], have studied structural, electrochemical and electrical analysis of polythiophene-carbon nanocomposite materials for fuel cell applications. They have also

Table 2. Electrical parameters of pure PTh and PTh /CdSe nanocomposites.

\begin{tabular}{|l|c|c|}
\hline \multicolumn{1}{|c|}{$\begin{array}{c}\text { Electrical } \\
\text { parameters }\end{array}$} & Pure PTh & $\begin{array}{c}\text { PTh/CdSe } \\
\text { nanocomposites }\end{array}$ \\
\hline Current & $4.5 \cdot 10^{-11}\left[10^{-2} \mathrm{nA}\right]$ & $2.5 \cdot 10^{-8}\left[10^{-2} \mu \mathrm{A}\right]$ \\
\hline DC conductivity & $10^{-9} \mathrm{~S} \cdot \mathrm{cm}^{-1}$ & $10^{-7} \mathrm{~S} \cdot \mathrm{cm}^{-1}$ \\
\hline Short circuit current & $10^{-5} \mu \mathrm{A} \cdot \mathrm{cm}^{-2}$ & $3.5 \cdot 10^{-3} \mathrm{~mA} \cdot \mathrm{cm}^{-2}$ \\
\hline
\end{tabular}

measured the current density using cyclic voltamogram method. The reported average current density was of the order of $10^{-3} \mathrm{~mA} \cdot \mathrm{cm}^{-2}$. The electrical parameters of pure PTh and its nanocomposites have been measured and calculated and the results are summarized in Table 2.

\subsection{UV-Visible spectroscopic analysis}

The optical properties of pure PTh and PTh/CdSe nanocomposites were analyzed by UV-visible spectroscopy as shown in Figures 10 and 11, respecctively. Figure 10 shows the strong absorption peak at $240 \mathrm{~nm}$ for native polythiophene might be due to $\pi-\pi^{*}$ transition of the conjugated structure of thiophene unit. This strong absorption peak is slightly shifted towards higher wavelength side $(260 \mathrm{~nm})$, well within the UV region, in the case of $\mathrm{PTh} / \mathrm{CdSe}$ nanocomposites. The absorption spectra show broad-

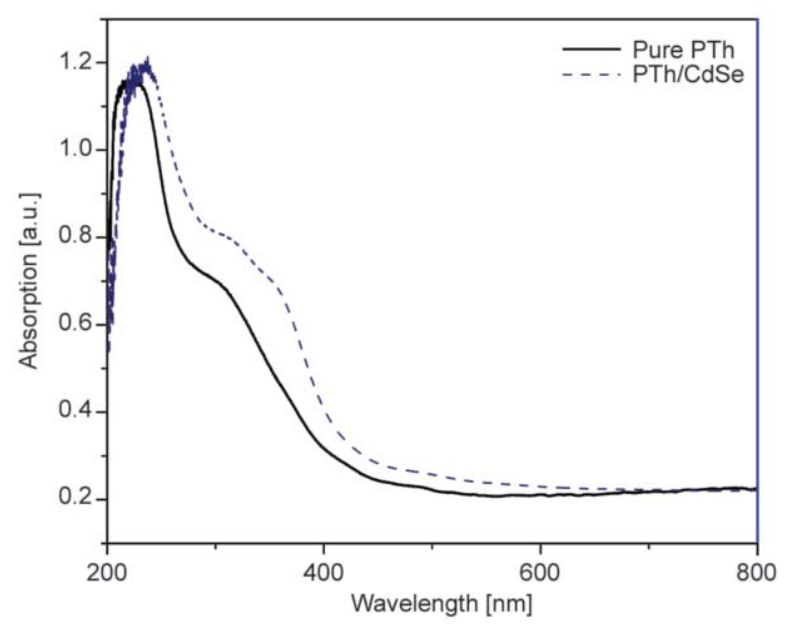

Figure 10. Absorption spectra of pure $\mathrm{PTh}$ and $\mathrm{PTh} / \mathrm{CdSe}$ nanocomposites. 

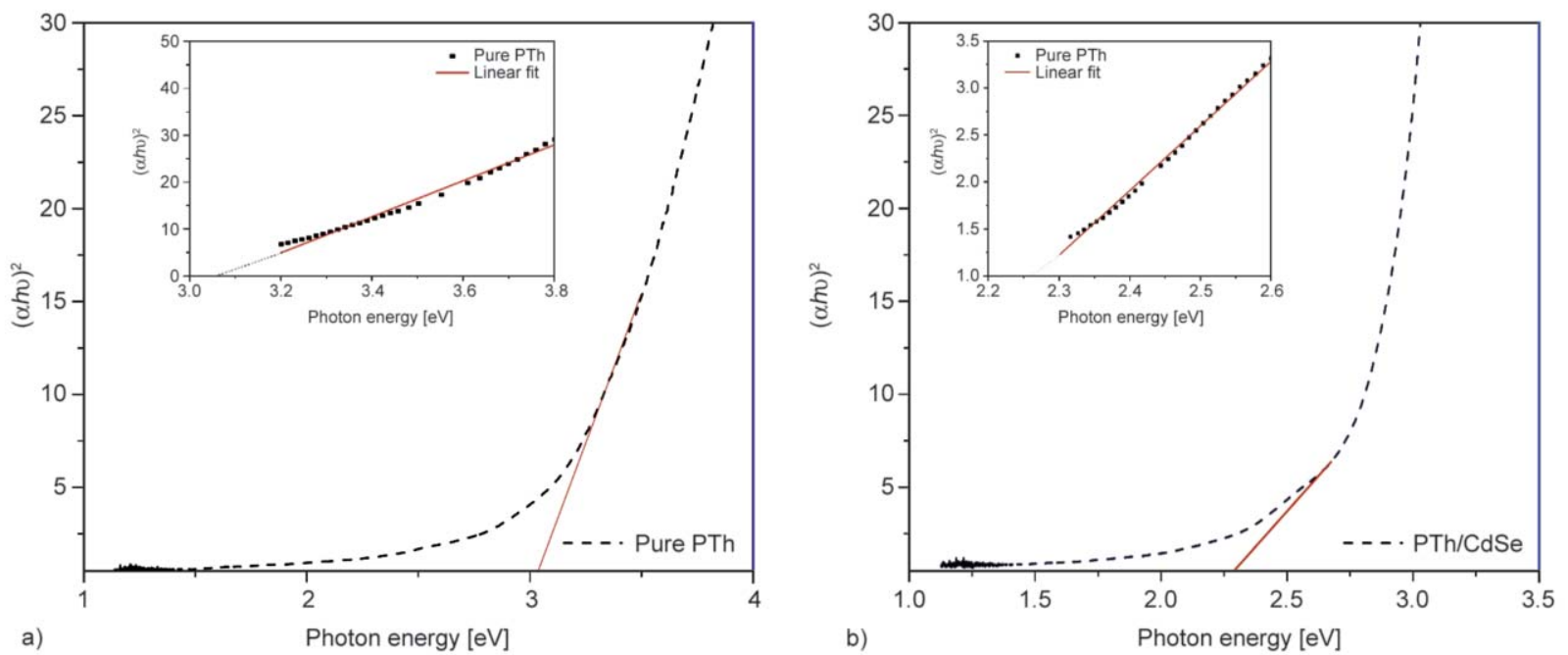

Figure 11. (a) Tauc plot of pure PTh, (b) Tauc plot of PTh/CdSe nanocomposites.

ening whose edge can be seen to be shifted towards higher wavelength side, when $\mathrm{CdSe}(\mathrm{S})$ nanoparticles are reinforced into the PTh matrix. This spectral shift might be caused by the presence of CdSe (S) particles in the PTh matrix when $\mathrm{PTh} / \mathrm{CdSe}(\mathrm{S})$ nanocomposites are formed, as reported by Vijet et al. [37] and Kamat et al. [52].

HOMO stands for 'Highest Occupied Molecular Orbital' and LUMO stands for 'Lowest Unoccupied Molecular Orbital'. LUMO is higher in energy than that of the HOMO. The HOMO-LUMO gap is that where the most likely excitation can occur. The HOMOLUMO gap is determined by the HOMO of the donor and the LUMO of the acceptor. Amna et al. [17] and Facchetti [55] have, has reported theoretically calculated the band gap of P3HT (Polythiophene family) for the LUMO level in the range of $3-4.7 \mathrm{eV}$ and for HOMO level of the order of $4-5.5 \mathrm{eV}$. HOMO-LUMO gap strongly depends on the degree of electron delocalization. HOMO-LUMO gap for the PTh and PTh/CdSe nanocomposites, can be obtained from absorption maxima and absorption onset, respectively.

The energy band gap $\left(E_{\mathrm{g}}\right)$ was calculated from the absorption spectra using the Tauc relationship (Equation (15)):

$(\alpha h v)=A\left(h v-E_{\mathrm{g}}\right)^{\mathrm{n}}$

where $A$ is a constant, $\alpha$ is the absorption coefficient, $h v$ is the photon energy, $\left(E_{\mathrm{g}}\right)$ is the optical band gap of the material and an exponent $n$, which depends on the type of transition. The $n$ may have values $1 / 2,2$, $3 / 2$ and 3 corresponding to the allowed direct,
Table 3. Pure PTh and PTh/CdSe nanocomposites.

\begin{tabular}{|l|l|l|c|c|}
\hline & Equation & Parameters & $\begin{array}{c}\text { Numerical } \\
\text { values }\end{array}$ & $\begin{array}{c}\text { Standard } \\
\text { error }\end{array}$ \\
\hline \multirow{2}{*}{ Pure PTh } & \multirow{2}{*}{$y=a+b x$} & Intercept & -14.57453 & 0.06905 \\
\cline { 3 - 5 } & & Slope & 6.86833 & 0.02822 \\
\hline \multirow{2}{*}{$\mathrm{PTh} / \mathrm{CdSe}$} & \multirow{2}{*}{$y=a+b x$} & Intercept & -118.2135 & 0.92242 \\
\cline { 3 - 5 } & & Slope & 38.46637 & 0.26191 \\
\hline
\end{tabular}

allowed indirect, forbidden direct and forbidden indirect transitions, respectively $[29,58,59]$.

Figure 11 shows the plots of $(\alpha h v)^{2} v s$. $h v$ for native $\mathrm{PTh}$ and $\mathrm{PTh} / \mathrm{CdSe}$ nanocomposites, respectively. Linear fit by extrapolating the linear portion over the set of data $(\mathrm{X}-\mathrm{Y})$ are shown in inset. The characteristic parameters of the tangent line drawn in the linear fit are summarized in Table 3.

Using the above equation given in Table 3 , the intercept and gradient were calculated. The value of intercept gives the energy band gap. By extrapolating the linear portion the band gap was calculated to be $3.05 \mathrm{eV}$ for PTh, and $2.26 \mathrm{eV}$ for composite, respectively. The reduction in energy band gap of $\mathrm{PTh} / \mathrm{CdSe}$ composite may lead to an increased conductivity which is a desirable property for employing the material in optical, optoelectronics, LED devices etc.

\section{Conclusions}

The present work deals with the synthesis of conducting polymer (PTh), semiconductor (CdSe), and their nanocomposite materials which deserve to be proposed for diode applications. This application is the reflection of CdSe nano-rods reinforced PTh nanocomposites by virtue of which the conductivity of the material is enhanced. For developing electronic 
devices such as diodes, semiconductor nanoparticles of CdSe are reinforced into PTh matrix by oxidation polymerization method using ferric chloride $\left(\mathrm{FeCl}_{3}\right)$ as a polymerization initiator. This method rapidly produces larger yields of polymer nanocomposites and is cost effective also. FESEM images confirm the presence of CdSe in PTh matrix. The EDAX data show the elemental composition of CdSe and PTh in the composites. Composite material shows a reduction in the energy band gap which is an indication of increased conductivity. Short circuit current in the nanocomposites is found to be higher than that of the native PTh. I-V characteristics of PTh/CdSe show an ohmic behavior at lower potential, while at higher potentials it responses like an organic-inorganic hetrojunction diode. The electrical measurements show that when CdSe nano-rods are reinforced into PTh nanocomposites, it behaves like a junction diode. Short circuit current and DC conductivity of such heterojunction are also increased in the composite phase in comparison to that in those of pure PTh. DC conductivity of organic-inorganic, $\mathrm{PTh} / \mathrm{CdSe}$ nanocomposites resembles with that of the heterojunction diode characteristics. These findings open up the possibility of its possible use as junction diode, protective devices, electronic devices, memory devices and designing energy storage devices in the device applications.

\section{Acknowledgements}

The materials were characterized at Raja Ramanna Center for Advanced Technology (RRCAT) Indore (MP), India and Central Instrumentation Facility (CIF), Jiwaji University, Gwalior, India. The authors acknowledge the RRCAT and CIF authorities for the facilities extended for the present work.

\section{References}

[1] Dunlop M. J., Bissessur R.: Nanocomposites based on graphene analogous materials and conducting polymers: A review. Journal of Material Science, 55, 6721-6753 (2020). https://doi.org/10.1007/s10853-020-04479-9

[2] Kaloni T. P., Giesbrecht P. K., Schreckenbach G., Freund M. S.: Polythiophene: From fundamental perspectives to applications. Chemistry of Materials, 29, 1024810283 (2017). https://doi.org/10.1021/acs.chemmater.7b03035

[3] Kaur G., Adhikari R., Cass P., Bown M., Gunatillake P.: Electrically conductive polymers and composites for biomedical applications. RSC Advances, 5, 37553 37567 (2015).

https://doi.org/10.1039/c5ra01851j
[4] Bakhshi A. K., Balla G.: Electrically conducting polymers: Materials of the twentyfirst century. Journal of Scientific and Industrial Research, 63, 715-728 (2004).

[5] Khanmohammadi S., Babazadeh M.: Synthesis of polythiophene/manganese dioxide nanocomposites by insitu core-shell polymerization method and study of their physical properties. Journal of Nanostructures, 8, 366373 (2018).

https://doi.org/10.22052/JNS.2018.04.006

[6] Deshpande M. D., Kondawar S. B.: Electrical conductivity of multi-walled carbon nanotubes doped conducting polythiophene. International Journal of Research in Applied Science and Engineering, 2, 24-30 (2014).

[7] Heeger A. J.: Semiconducting and metallic polymers: The fourth generation of polymeric materials. The Journal of Physical Chemistry B, 105, 8475-8491 (2001). https://doi.org/10.1021/jp011611w

[8] MacDiarmid A. G.: 'Synthetic metals': A novel role for organic polymers (Nobel lecture). Angewandte Chemie International Edition, 40, 2581-2590 (2001).

https://doi.org/10.1002/1521-

3773(20010716)40:14<2581::AID-ANIE2581>3.0.CO;2-2

[9] Senthilkumar S., Rajendran A.: Synthesis, characterization and electrical properties of nano metal and metaloxide doped with conducting polymer composites by in-situ chemical polymerization. MOJ Polymer Science, 1, 192-195 (2017).

https://doi.org/10.15406/mojps.2017.01.00031

[10] Ozkazanc H.: Novel nanocomposites based on polythiophene and zirconium dioxide. Materials Research Bulletin, 73, 226-232 (2016).

https://doi.org/10.1016/j.materresbull.2015.09.009

[11] Khan A. A., Baig U.: Electrical conductivity and ammonia sensing studies on in situ polymerized poly(3methythiophene)-titanium(IV)molybdophosphate cation exchange nanocomposite. Sensors and Actuators B: Chemical, 177, 1089-1097 (2013). https://doi.org/10.1016/j.snb.2012.11.087

[12] Guo X-Z., Kang Y-F., Yang T-L., Wang S-R.: Low-temperature $\mathrm{NO}_{2}$ sensors based on polythiophene/ $\mathrm{WO}_{3}$ organic-inorganic hybrids. Transactions of Nonferrous Metals Society of China, 22, 380-385 (2012). https://doi.org/10.1016/S1003-6326(11)61187-4

[13] Bora C., Pegu R., Saikia B. J., Dolui S. K.: Synthesis of polythiophene/graphene oxide composites by interfacial polymerization and evaluation of their electrical and electrochemical properties. Polymer International, 63, 2061-2067 (2014). https://doi.org/10.1002/pi.4739

[14] Otsuka Y., Okamoto Y., Akiyama H. Y., Umekita K., Tachibana Y., Kuwabata S.: Photoinduced formation of polythiophene $/ \mathrm{TiO}_{2}$ nanohybrid heterojunction films for solar cell applications. Journal of Physical Chemistry C, 112, 4767-4775 (2008). https://doi.org/10.1021/jp7099064

[15] Tembhe J. A., Waghuley S. A.: Synthesis and gas sensing application of conducting polymer-polythiophene nanocomposite. International Journal of Current Engineering and Scientific Research, 5, 182-186 (2018). 
[16] Skotheim T. A., Reynolds J.: Handbook of conducting polymers. CRC Press, Boca Raton (2007).

[17] Amna B., Siddiqi H. M., Hassan A., Ozturk T.: Recent developments in the synthesis of regioregular thiophene-based conjugated polymers for electronic and optoelectronic applications using nickel and palladiumbased catalytic systems. RSC Advances, 10, 4322-4396 (2020). https://doi.org/10.1039/C9RA09712K

[18] Chandraprabha G., Sankarappa T., Lokhande B. J., Sujatha T.: Studies on conduction mechanism, magnetization and electrochemical properties of polythiophene-cobalt nanocomposites. Journal of Nanoscience and Technology, 4, 304-307 (2018).

https://doi.org/10.30799/jnst.092.18040101

[19] Patil B. H., Jagadale A. D., Lokhande C. D.: Synthesis of polythiophene thin films by simple successive ionic layer adsorption and reaction (SILAR) method for supercapacitor application. Synthetic Metals, 162, 1400 1405 (2012).

https://doi.org/10.1016/j.synthmet.2012.05.023

[20] Mastour N., Hamed Z. B., Benchaabane A., Sanhoury M. A., Kouki F.: Effect of ZnSe quantum dot concentration on the fluorescence enhancement of polymer P3HT film. Organic Electronics, 14, 2093-2100 (2013). https://doi.org/10.1016/j.orgel.2013.05.005

[21] Mastour N., Bouchriha H.: Effect of CdSe nanoparticles on the fluorescence spectra of conjugate polymer P3HT: An experimental and theoretical study. Physics Letters A, 380, 3866-3869 (2016). https://doi.org/10.1016/j.physleta.2016.09.047

[22] Najar M. H., Majid K.: Synthesis, characterization, electrical and thermal properties of nanocomposite of polythiophene with nanophotoadduct: A potent composite for electronic use. Journal of Materials Science: Materials in Electronics, 24, 4332-4339 (2013).

https://doi.org/10.1007/s10854-013-1407-8

[23] Beek W. J. E., Wienk M. M., Janssen R. A. J.: Hybrid solar cells from regioregular polythiophene and $\mathrm{ZnO}$ nanoparticles. Advanced Functional Materials, 16, 1112-1116 (2006).

https://doi.org/10.1002/adfm.200500573

[24] Harito C., Bavykin D. V., Yuliarto B., Dipojono H. K., Walsh F. C.: Polymer nanocomposites having a high filler content: Synthesis, structures, properties, and applications. Nanoscale, 11, 4653-4682 (2019). https://doi.org/10.1039/C9NR00117D

[25] Liang Y. F., Deng S. J., Xia Y., Wang X. L., Xia X. H., Wu J. B., Gu C. D., Tu J. P.: A superior composite gel polymer electrolyte of $\mathrm{Li}_{7} \mathrm{La}_{3} \mathrm{Zr}_{2} \mathrm{O}_{12}$ - poly(vinylidene fluoride-hexafluoropropylene) (PVDF-HFP) for rechargeable solid-state lithium ion batteries. Materials Research Bulletin, 102, 412-417 (2018). https://doi.org/10.1016/j.materresbull.2018.02.051

[26] Thirugnanam N., Govindarajan D.: Effect of Ni doping on the structural, optical and morphological properties of CdSe QDs by chemical precipitation method. Journal of Materials Science: Materials in Electronics, 27, 4571-4577 (2016).

https://doi.org/10.1007/s10854-016-4333-8
[27] Hosseini M. S., Khorashahi S., Hosseini N.: Synthesis of 2-mercaptonicotinic acid-capped cdse quantum dots and its application to spectrofluorometric determination of $\mathrm{Cr}(\mathrm{VI})$ in water samples. Journal of Fluorescence, 26, 867-874 (2016).

https://doi.org/10.1007/s10895-016-1774-7

[28] Khmelinskii I., Makarov V. I.: Optical properties of $\mathrm{ZnO}$ semiconductor nanolayers. Material Research Bulletin, 109, 291-300 (2019).

https://doi.org/10.1016/j.materresbull.2018.09.030

[29] Heiba Z. K., Mohamed M. B., Imam N. G., Mostafa N. Y.: Optical and electrical properties of quantum composite of polyvinyl alcohol matrix with CdSe quantum dots. Colloid and Polymer Science, 294, 357-365 (2016). https://doi.org/10.1007/s00396-015-3793-3

[30] Ahmed R. M., Morsi R. M. M.: Polymer nanocomposite dielectric and electrical properties with quantum dots nanofiller. Modern Physics Letters B, 31, 1750278/11750278/18 (2017). https://doi.org/10.1142/S0217984917502785

[31] Acharya A., Sahu S., Balamurgan S., Roy G. S.: Effect of doping on nano cadmium-selenide (CdSe) - assessment through UV-VIS spectroscopy. Latin-American Journal of Physics Education, 5, 134-139 (2011).

[32] Acharya A., Mishra R. K., Roy G. S.: Comparative study of performance of CdS, CdSe thin film CdS-PTh, CdSe-PTh nanocomposite thin films using scanning electron microscope and fourier transform infrared spectroscopy. Latin-American Journal of Physics Education, 4, 603-609 (2010).

[33] AlFannakh H., Arafat S. S., Ibrahim S. S.: Synthesis, electrical properties, and kinetic thermal analysis of polyaniline/polyvinyl alcohol - magnetite nanocomposites film. Science and Engineering of Composite Materials, 26, 347-359 (2019). https://doi.org/10.1515/secm-2019-0020

[34] Yao J., Zhao G., Han G.: Synthesis and characterization of the thiourea-capped CdS nanoparticles. Journal of Material Science Letters, 22, 1491-1493 (2003). https://doi.org/10.1023/A:1026194929224

[35] Murugavel S., Malathi M.: Synthesis and characterization of polythiophene nanofibers. International Journal of Chemical Science, 14, 363-371 (2016).

[36] Chao P-J., Wang Y-J., Lin F-H.: The growth of CdSe quantum dots on a single wall carbon nanotubes template without organic solvent and surfactant. Ceramics International, 38, 547-552 (2012). https://doi.org/10.1016/j.ceramint.2011.07.042

[37] Vijeth H., Yesappa L., Niranjana M., Ashokkumar S. P., Devendrappa H.: Investigation on structural, optical and electrical properties of polythiophene- $\mathrm{Al}_{2} \mathrm{O}_{3}$ composites. AIP Conference Proceeding, 1953, 05000/1050008/4 (2017). https://doi.org/10.1063/1.5032663 
[38] Silva R. A., Santos M. J. L., Rinaldi A. W., Jarbin A. J. G., Oliverira M. M., Santos I. A., Cótica L. F., Coellho A. A., Rubira A. F., Girotto E. M.: Low coercive field and conducting nanocomposite formed by $\mathrm{Fe}_{3} \mathrm{O}_{4}$ and poly(thiophene). Journal of Solid State Chemistry, 180, 3545-3550 (2007).

https://doi.org/10.1016/j.jssc.2007.10.018

[39] Singh R., Bajpai A. K., Shrivastava A. K.: CdSe nanorod-reinforced poly(thiophene) composites in designing energy storage devices: Study of morphology and dielectric behavior. Polymer Bulletin, in press (2020). https://doi.org/10.1007/s00289-020-03104-8

[40] Patidar D., Jain N., Saxena N. S., Sharma K., Sharma T. P.: Electrical properties of CdS/polyaniline heterojunction. Brazilian Journal of Physics, 36, 1210-1212 (2006).

https://doi.org/10.1590/S0103-97332006000700016

[41] Pourabbas B., Foroutani K., Mohammadizadeh M., Fallahian M.: Conductive polythiophene nanoparticles deposition on transparent pet substrates: Effect of modification with hybrid organic-inorganic coating. international. Journal of Engineering Transactions A: Basics, 28, 593-598 (2015).

[42] Tiwari D. C., Sen V., Sharma R.: Temperature dependent studies of electric and dielectric properties of polythiophene based nanocomposites. Indian Journal of Pure and Applied Physics, 50, 49-56 (2012).

[43] Phukan P., Saikia D.: Optical and structural investigation of CdSe quantum dots dispersed in PVA matrix and photovoltaic applications. International Journal of Photoenergy, 2013, 728280/1-728280/6 (2013).

https://doi.org/10.1155/2013/728280

[44] Singh N., Singh J., Kumar S., Kumar M., Gaur A., Sirohi K.: Electrical measurements of polyaniline and $\mathrm{CdS}$ heterojunction. International Journal of Research in Applied, Natural and Social Sciences, 1, 9-12 (2013).

[45] Kaneto K., Yoshino K., Inuishi Y.: Electrical and optical properties of polythiophene prepared by electrochemical polymerization. Solid State Communication, 46, 389-391 (1983).

https://doi.org/10.1016/0038-1098(83)90454-4

[46] Nasrollahzadeh M., Jahanshahi M., Yaldagard M., Salehi M.: Synthesis, characterization and comparison of polythiophene-carbon nanocomposite materials as Pt electrocatalyst supports for fuel cell applications. Bulletin of Material Science, 41, 85/1-85/8 (2018).

https://doi.org/10.1007/s12034-018-1599-x

[47] Khan A., Asiri A. M., Khan A. A. P., Khan S. B.: Electrical conductivity and ion-exchange kinetic studies of polythiophene $\mathrm{Sn}(\mathrm{VI})$ phosphate nanocomposite cationexchanger. Arabian Journal of Chemistry, 12, 1652 1659 (2019).

https://doi.org/10.1016/j.arabjc.2014.09.004

[48] Kattimani J., Sankarappa T., Ashwajeet J. S., Ramanna R., Praveenkumar K., Chandraprabha G.: DC conduction in polythiophene nanocomposites doped with $\mathrm{V}_{2} \mathrm{O}_{5}$. Research Journal of Material Science, 3, 6055/16055/6 (2015).
[49] Ali H. M., Abd El-Ghanny H. A.: Investigation of the structural, optical and electrical transport properties of n-doped CdSe thin films. Journal of Physics: Condensed Matter, 20, 155205/1-155205/8 (2008).

https://doi.org/10.1088/0953-8984/20/15/155205

[50] Rosmani C. H., Zainurul A. Z., Rusop M., Abdullah S.: The optical and electrical properties of CdSe nanoparticles. Advanced Materials Research, 832, 557-561 (2014).

https://doi.org/10.4028/www.scientific.net/AMR.832.557

[51] Patidar D., Rathore K. S., Saxena N. S., Sharma K., Sharma T. P.: Energy band gap and conductivity measurement of CdSe thin films. Chalcogenide Letters, $\mathbf{5}$, 21-25 (2008).

[52] Kamat S. V., Tamboli S. H., Puri V., Puri R. K., Yadav J. B., Joo O. S.: Optical and electrical properties of polythiophene thin films: Effect of post deposition heating. Journal of Optoelectronics and Advanced Materials, 12, 2301-2305 (2010).

[53] Yesappa L., Niranjana M., Ashokkummar S., Vijeth H., Raghu S., Devendrappa H.: Characterization, electrical conductivity and electrochemical performance of polyaniline- $\mathrm{LiClO}_{4}-\mathrm{CuO}$ nano composite for energy storage applications. Polymer Plastic Technology and Engineering, 58, 193-205 (2018).

https://doi.org/10.1080/03602559.2018.1466175

[54] Singh R., Shrivastava A. K., Bajpai A. K.: CdSe reinforced polyaniline nanocomposites as superior material for future applications as gas sensor and diodes. Material Research Express, 6, 1250a9/1-1250a9/12 (2019). https://doi.org/10.1088/2053-1591/ab6127

[55] Facchetti A.: $\pi$-conjugated polymers for organic electronics and photovoltaic cell applications. Chemistry of Materials, 23, 733-758 (2011).

https://doi.org/10.1021/cm102419z

[56] Seidler N., Lazzerini G. M., Destri G. L., Marletta G., Cacialli F.: Enhanced crystallinity and film retention of P3HT thin-films for efficient organic solar cells by use of preformed nanofibers in solution. Journal of Materials Chemistry C, 1, 7748-7757 (2013). https://doi.org/10.1039/C3TC31284D

[57] Vijeth H., Ashokkumar S. P., Yesappa L., Niranjana M., Vandana M., Devendrappa H.: Flexible and high energy density solid-state asymmetric supercapacitor based on polythiophene nanocomposites and charcoal. RSC Advances, 8, 31414-31426 (2018). https://doi.org/10.1039/c8ra06102e

[58] Khanna P. K., Singh N., Charan S., Lonkar S. P., Reddy A. S., Patil Y., Viswanath A. K.: The processing of CdSe/ polymer nanocomposites via solution organometallic chemistry. Materials Chemistry and Physics, 97, 288294 (2006).

https://doi.org/10.1016/j.matchemphys.2005.08.012

[59] Heiba Z. K., Mohammed M. B., Imam N. G.: Biphasic quantum dots of cubic and hexagonal Mn doped CdS; necessity of Rietveld analysis. Journal of Alloys and Compound, 618, 280-286 (2015).

https://doi.org/10.1016\%2Fj.jallcom.2014.08.106 